\title{
Study on the Absorption Properties of Sulfonated Aluminum Phthalocyanine IN VIVO AND EX VIVO IN MURINE TUMOR MODELS
}

\author{
Rinaldo Cubeddu, ${ }^{\dagger}$ Gianfranco Canti, ${ }^{\dagger}$ Antonio Pifferi, ${ }^{\dagger}$ Paola Taroni, ${ }^{\dagger}$ \\ Alessandro Torricelli, ${ }^{\dagger}$ and Gianluca Valentini ${ }^{\dagger}$ \\ ${ }^{\dagger}$ Politecnico di Milano, C.E.Q.S.E.-C.N.R., Piazza L. da Vinci 32, 20133 Milan, Italy; ${ }^{\dagger}$ University of \\ Milan, Department of Pharmacology, Milan, Italy \\ (Paper JBO-092 received May 13, 1996; revised manuscript received Sep. 30, 1996; accepted for publication Oct. 3, 1996.)
}

\begin{abstract}
The absorption spectrum of aluminum phthalocyanine with a mean degree of sulfonation of $2.1\left(\mathrm{AlPcS}_{2}\right)$, previously measured in vivo in a murine tumor model (L1210 leukemia), showed a significant (10 to $15 \mathrm{~nm}$ ) red shift with respect to the spectrum in solution and in vitro. To investigate whether this behavior was due to the peculiar model considered (ascitic tumor), the absorption line shape was evaluated in vivo noninvasively in a solid tumor (murine MS-2 fibrosarcoma) by means of time-resolved reflectance. The spectrum

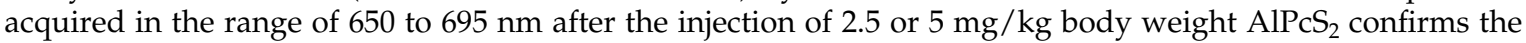
red shift to 680 to $685 \mathrm{~nm}$. Experiments performed ex vivo suggest that the spectral shift is related to the interactions of the drug with the extracellular biological substrate and depends on the sensitizer concentration. () 1997 Society of Photo-Optical Instrumentation Engineers.
\end{abstract}

Keywords absorption spectrum; in vivo absorption; photosensitizers; phthalocyanine; time-resolved reflectance.

\section{INTRODUCTION}

The correct choice of irradiation wavelength is a key element for the successful application of photodynamic therapy of tumors. In its turn, the ability to determine the optimal irradiation wavelength is based on the knowledge of both the optical properties of tissue and the exact absorption line shape of the photosensitizer in vivo.

Among the second-generation sensitizers at present under study, sulfonated phthalocyanines have proved especially efficient both in vitro and in vivo. ${ }^{1,3}$ In the past few years, various research groups have devoted particular interest to aluminum phthalocyanine either disulfonated or with a mean degree of sulfonation of $2\left(\mathrm{AlPcS}_{2}\right) \cdot{ }^{2,4-6}$ In solution in various solvents as well as incorporated in detergent micelles and in the presence of excess concentrations of albumin, this compound is characterized by an intense absorption in the red region of the spectrum, always centered at $672 \mathrm{~nm}$ or shifted by no more than $4 \mathrm{~nm} .^{7}$

The recent development of reflectance techniques, either time resolved or continuous wave, ${ }^{8}$ allowed the measurement of the absorption spec-

Address all correspondence to Rinaldo Cubeddu. E-mail: cubeddu@axp7000.cdc.polimi.it trum of $\mathrm{AlPcS}_{2}$ in vivo in normal and neoplastic tissues. A limited bathochromic shift in vivo had already been observed by other authors, ${ }^{9,10}$ even though in preliminary nonsystematic studies. In a recent work we reported on the spectrum obtained from an ascitic tumor (L1210 lymphoid leukemia) in mice. ${ }^{11}$ The absorption line shape in vivo peaks at about $685 \mathrm{~nm}$ and is red shifted 10 to $15 \mathrm{~nm}$ compared with the situation in solution.

To determine whether the shift was to be attributed to the peculiar features of the tumor model previously considered (i.e., an ascitic tumor in the peritoneum), in the present study the absorption line shape of $\mathrm{AlPcS}_{2}$ was measured in vivo in a solid tumor (MS-2 fibrosarcoma) in mice. The results indicate that the red shift depends neither on the kind of tumor nor its location. To get a deeper insight into the origin of the different absorption properties in vivo, measurements were performed ex vivo on the L1210 ascites of treated animals and on the ascites of untreated mice incubated in vitro with the drug. The red shift of the absorption line shape can be observed in both cases. It is influenced by the drug concentration and seems to be caused by the

1083-3668/97/\$10.00 @ 1997 SPIE 
interactions of the drug with the extracellular environment of the biological substrate.

\section{MATERIAls AND MeTHOdS}

\subsection{CHEMICALS}

Aluminum phthalocyanine with an average degree of sulfonation of 2.1 (hereafter called disulfonated aluminum phthalocyanine, $\mathrm{AlPcS}_{2}$ ) was kindly provided by Dr. A. McLennan (Paisley College of Technology, Paisley, UK) and diluted in saline at a concentration of $2.5 \mathrm{mg} / \mathrm{ml}$. The mean degree of sulfonation was ascertained by means of chromatography. The compound consists of a mixture of isomers with sulfonic groups in both adjacent and opposite positions.

\subsection{ANIMALS AND TUMOR MODELS}

Both in vivo and ex vivo experiments were performed on hybrid (Balb/c $\left.\times \mathrm{DBA} / 2 \mathrm{~F}_{1}\right)$ mice (Charles River, Calco, Italy). The MS-2 fibrosarcoma, originally induced by the Moloney murine sarcoma virus, was maintained by weekly intramuscular passage of tumor cell homogenate into the right hind leg. For in vivo reflectance measurements, tumor cells $\left(10^{6}\right.$ cells/mouse) were injected intradermally (i.d.) into the back of the mice and the experiments were carried out 6 days later.

The chemically induced L1210 lymphoid leukemia was maintained by weekly intraperitoneal (i.p.) injection. For the ex vivo measurements as well, tumor cells $\left(10^{6}\right.$ cells / mouse) were injected intraperitoneally and the experiments were performed 5 days later.

\subsection{IN VIVO MEASUREMENTS}

\subsubsection{Instrumentation for Time-Resolved Reflectance}

The system is described in detail in Cubeddu et al. ${ }^{12}$ A cavity-dumped dye (DCM) laser (Coherent model CR-599, Palo Alto, California) pumped by a mode-locked argon laser (Coherent model CR18, Palo Alto, California) was used as the light source, tunable between 650 and $695 \mathrm{~nm}$. The pulse duration was $<10$ ps, with a repetition rate of 3.5 $\mathrm{MHz}$.

One-millimeter plastic-glass fiber optics (Quartz \& Silice model PCS1000, Paris, France) were used for both illumination and collection. The illumination fiber was placed in contact with the animal skin by means of a fiber holder. The laser power at the distal end of the fiber was $<10 \mathrm{~mW}$. The reflected light was collected by a second identical fiber, again in contact with the skin surface. The two fibers were set at a relative distance of $0.8 \mathrm{~cm}$ parallel to each other. The distal end of the collection fiber was positioned at the entrance slit of a scanning monochromator. A small fraction of the laser beam was split off and sent directly to the mono- chromator, to provide a time reference and account for eventual time drifts of the electronic instrumentation.

The reflectance photons were detected by a double microchannel plate photomultiplier (Hamamatsu model R1564U-01, Bridgewater, New Jersey) and the signal was suitably amplified by means of a fast preamplifier (EG\&G model VT120A, Oak Ridge, Tennessee) and a homedesigned integrating amplifier. An electronic chain for time-correlated single-photon counting was used to measure the time-resolved reflectance. At each wavelength, the experimental reflectance decay curves were collected by a multichannel analyzer (Silena model Varro, Milan, Italy) and transferred to a personal computer for data storage and analysis.

The system response had a typical full width at half-maximum $\leqslant 60$ ps and a time drift $<1 \mathrm{ps} / \mathrm{min}$. The spectral resolution was $\cong 2 \mathrm{~nm}$.

The theoretical reflectance, as described in the diffusion model, ${ }^{13}$ was convoluted with the system response and fitted to the measured reflectance, once the uncorrelated background had been subtracted. The best-fitting parameters were obtained by means of an iterative procedure, based on a generalized reduced-gradient algorithm to minimize the reduced $\chi^{2}{ }^{14}$

\subsubsection{Experimental Procedure}

Two drug doses [2.5 and $5 \mathrm{mg} / \mathrm{kg}$ body weight (b.w.) injected i.p.] were considered. With both of them, the experiment was carried out twice. Each time and for each drug dose, the measurements were performed on a group of 4 animals with the following procedure.

Six days after the passage of MS-2 tumor cells, the mice were caged in a plastic box, with a hole centered at the tumor site (on the animal's back). The fiber holder was placed in contact with the skin lining the tumor mass and reflectance measurements were performed on untreated mice every $5 \mathrm{~nm}$ in the 650 to $695 \mathrm{~nm}$ range. For each mouse, after the first series of measurements, the fiber holder was moved and repositioned, and a second series was performed. The mice were then injected i.p. with 2.5 or $5 \mathrm{mg} / \mathrm{kg}$ b.w. of $\mathrm{AlPcS}_{2}$, and 1 and $3 \mathrm{~h}$ later the whole measurement procedure was repeated. At each wavelength $10^{5}$ counts were collected. This required $10 \mathrm{~s}$ to $2 \mathrm{~min}$, depending on the different illumination power and optical properties of tissue (either treated or untreated) at distinct wavelengths. The total acquisition time for a whole spectrum therefore varied between 2 and $5 \mathrm{~min}$.

Thus, at each drug dose, the absorption coefficient was evaluated twice as a function of wavelength both before and after drug administration, at the two selected times of observation. In order to assess the average absorption line shape of $\mathrm{AlPcS}_{2}$ in vivo, the two spectra taken from each untreated mouse were averaged. The average was subtracted 
Table 1 Absorption maximum $\lambda_{\max }$ of the supernatant incubated ex vivo with $\mathrm{AlPcS}_{2}$.

\begin{tabular}{ccc}
$\frac{\mu \mathrm{g} \mathrm{AlS}}{2} \mathrm{Pc}$ \\
$\mathrm{ml} \mathrm{total}$ & $\frac{\mu \mathrm{g} \mathrm{AlS}}{2} \mathrm{Pc}$ & \\
\hline 0.25 & 2.5 & $683-684$ \\
0.5 & 5 & $683-684$ \\
1 & 10 & $682-683$ \\
2.5 & 25 & $682-683$ \\
5 & 50 & $680-681$ \\
10 & 100 & $673-674$ \\
20 & 200 & 672 \\
\hline
\end{tabular}

from each of the two spectra acquired from the same mouse after drug administration. Then the resulting curves (total of 8 curves) relative to two repeated measurements on 4 animals in the same experimental conditions (drug dose and uptake time) were normalized in area and averaged, leading to the average line shape of the drug in vivo. The average absorption spectrum for treated and untreated animals was also calculated, together with the standard deviation at every wavelength.

The possibility of photobleaching of the sensitizer caused by the illumination light was tested by repeating a measurement twice without changing the fiber position. The test was performed at $680 \mathrm{~nm}$ on treated animals. No remarkable differences were noted between the results of the first and the second measure, indicating that possible photobleaching did not affect the experiments significantly.

\subsection{EX VIVO MEASUREMENTS}

Five experiments were performed to assess the dependence of the absorption properties of $\mathrm{AlPcS}_{2}$ on the dose and incubation protocol. In all the experiments and for each dose, the whole procedure was repeated on 3 animals and the absorption spectrum was assessed in the 600 to $720-\mathrm{nm}$ range by means of a commercial spectrophotometer (Perkin Elmer model 554 UV-VIS, Norwalk, Connecticut).

In a first set of measurements, 5 days after the intraperitoneal passage of tumor cells, groups of mice bearing the L1210 leukemia were administered 1, 2.5, 5, or $10 \mathrm{mg} / \mathrm{kg}$ b.w. of $\mathrm{AlPcS}_{2}$. One hour later, the animals were sacrificed and the ascites was drawn from the peritoneum and diluted 1:10 in saline $\left(10^{7}\right.$ cells $\left./ \mathrm{ml}\right)$. The absorption spectrum was acquired from part of the ascites, while the remaining volume was centrifuged, the cells were isolated and resuspended in saline $\left(10^{7}\right.$ cells/ $\mathrm{ml}$ ), and both cell suspension and supernatant were analyzed. The same series of measurements was
Table 2 Absorption maximum $\lambda_{\max }$ of the diluted supernatant (overall dilution 1:100 in saline) incubated ex vivo with $\mathrm{AlPcS}_{2}$.

\begin{tabular}{|c|c|c|}
\hline$\underline{\mu \mathrm{g} \mathrm{AlS}} \mathrm{Al}_{2}$ & $\mu \mathrm{g} \mathrm{AlS}{ }_{2} \mathrm{Pc}$ & \\
\hline $\mathrm{ml}$ total & ml supernatant & $\lambda_{\max }(\mathrm{nm})$ \\
\hline 0.25 & 25 & $681-682$ \\
\hline 0.5 & 50 & $679-680$ \\
\hline 1 & 100 & $673-674$ \\
\hline 2.5 & 250 & 672 \\
\hline
\end{tabular}

performed by sacrificing the animals $3 \mathrm{~h}$ instead of $1 \mathrm{~h}$ after drug administration.

In a second set of experiments, after sacrifice of untreated animals, the ascites was drawn from the peritoneum, diluted 1:10 in saline $\left(10^{7}\right.$ cells $\left./ \mathrm{ml}\right)$ and divided into two equal parts. One of them was centrifuged to isolate the cells. The supernatant and resuspended cells $\left(10^{7}\right.$ cells $\left./ \mathrm{ml}\right)$ obtained from centrifugation as well as the part of the ascites that had not been centrifuged were incubated for $1 \mathrm{~h}$ with AlPcS $_{2}[0.25,0.5,1,2.5,5,10$, or $20 \mu \mathrm{g} / \mathrm{ml}$ (see Table 1)]. After incubation, the cells were centrifuged, isolated, and resuspended in saline $\left(10^{7}\right.$ cells $\left./ \mathrm{ml}\right)$. Resuspended cells, supernatant, and ascites were measured separately.

A third set of measurements was performed by incubating the supernatant of untreated ascites after a further dilution 1:10 in saline. In detail, the ascites of untreated animals was drawn from the peritoneum, diluted 1:10 in saline and centrifuged. The supernatant was separated from the cells, diluted again 1:10 in saline and incubated with different amounts of $\mathrm{AlPcS}_{2}$. The drug concentrations considered were $0.25,0.5,1$, and $2.5 \mu \mathrm{g} / \mathrm{ml}$ (see Table 2).

A fourth set of experiments was carried out by incubating the undiluted ascites of untreated animals with $20 \mu \mathrm{g} / \mathrm{ml} \mathrm{AlPcS}{ }_{2}$ and diluting thereafter [1:10, 1:100 and 1:500 in saline (see Table 3)] for the absorption measurements. The incubated ascites was centrifuged, the cells were isolated, and the supernatant was measured.

Table 3 Absorption maximum $\lambda_{\max }$ of the supernatant when the undiluted ascites is incubated ex vivo with $20 \mu \mathrm{g} / \mathrm{ml} \mathrm{AlPcS}{ }_{2}$ and diluted thereafter.

\begin{tabular}{ccc}
$\frac{\mu \mathrm{g} \mathrm{AlS}}{\mathrm{ml} \mathrm{Pc}_{\mathrm{c}}}$ & $\frac{\mu \mathrm{g} \mathrm{Ala} \mathrm{Al}_{2} \mathrm{Pc}}{\mathrm{ml} \mathrm{ascites}}$ & $\lambda_{\max }(\mathrm{nm})$ \\
\hline 2 & 20 & $683-684$ \\
0.2 & 20 & $678-679$ \\
0.04 & 20 & $674-675$ \\
\hline
\end{tabular}


Table 4 Absorption maximum $\lambda_{\max }$ of the supernatant diluted in saline and incubated thereafter ex vivo with $20 \mu \mathrm{g} / \mathrm{ml} \mathrm{AlPcS}$.

\begin{tabular}{|c|c|c|}
\hline$\underline{\mu \mathrm{g} \mathrm{AlS}}{ }_{2} \mathrm{Pc}$ & $\mu \mathrm{g} \mathrm{AlS}{ }_{2} \mathrm{Pc}$ & \\
\hline $\mathrm{ml}$ total & $\overline{\mathrm{ml}}$ supernatant & $\lambda_{\max }(\mathrm{nm})$ \\
\hline 2 & 20 & $680-681$ \\
\hline 0.2 & 20 & $678-679$ \\
\hline 0.04 & 20 & 674 \\
\hline
\end{tabular}

Finally, after sacrifice of untreated animals, the ascites was drawn from the peritoneum, diluted 1:10 in saline, and centrifuged. The supernatant was either incubated directly or diluted in saline and thereafter incubated. The concentration of $\mathrm{AlPcS}_{2}$ per milliliter of supernatant was kept constant at 20 $\mu \mathrm{g} / \mathrm{ml}$, while the concentration of drug per milliliter of total volume was varied [0.04, 0.2, and 2 $\mu \mathrm{g} / \mathrm{ml}$ (see Table 4)].

The ascites, resuspended cells, or supernatant of control (untreated) animals were always used as a reference, in order to minimize the strong contribution of scattered light to the measured signal. The same dilution in saline was used for both sample and reference.

\section{RESULTS}

\subsection{IN VIVO MEASUREMENTS}

Figure 1 (open circles) shows the average absorption spectrum acquired in vivo from the tumor area of mice bearing the MS-2 fibrosarcoma before drug administration. The standard deviations at the different wavelengths are also reported. In the range of observation (650 to $695 \mathrm{~nm}$ ), the average absorption coefficient $\mu_{\mathrm{a}}$ decreases progressively from about $0.65 \mathrm{~cm}^{-1}$ to about $0.4 \mathrm{~cm}^{-1}$ with increasing wavelength.

The administration of $\mathrm{AlPcS}_{2}$ causes an increase in absorbance mainly between 670 and $690 \mathrm{~nm}$. One hour after the i.p. injection of $2.5 \mathrm{mg} / \mathrm{kg} \mathrm{b.w}$. of drug, a very broad absorption maximum is observed at $680 \mathrm{~nm}$. The average spectrum with the standard deviations of treated animals is shown in Figure 1 (closed circles). Concerning the absolute values of the absorption coefficient, drug administration causes an average increase of about 0.3 $\mathrm{cm}^{-1}$ at $680 \mathrm{~nm}$.

The average absorption line shape of $\mathrm{AlPcS}_{2}$ (2.5 $\mathrm{mg} / \mathrm{kg}$ b.w., $1 \mathrm{~h}$ incubation time), as obtained by subtraction, is shown in Figure 2 with the standard deviations for 8 measurements (two repeated measurements on 4 different animals). It is compared with the absorption line shape of $\mathrm{AlPcS}_{2}$ (2.5 $\mu \mathrm{g} / \mathrm{ml}$ ) in aqueous solution: the absorption peak is centered between 680 and $685 \mathrm{~nm}$ in vivo and at 672 $\mathrm{nm}$ in solution.

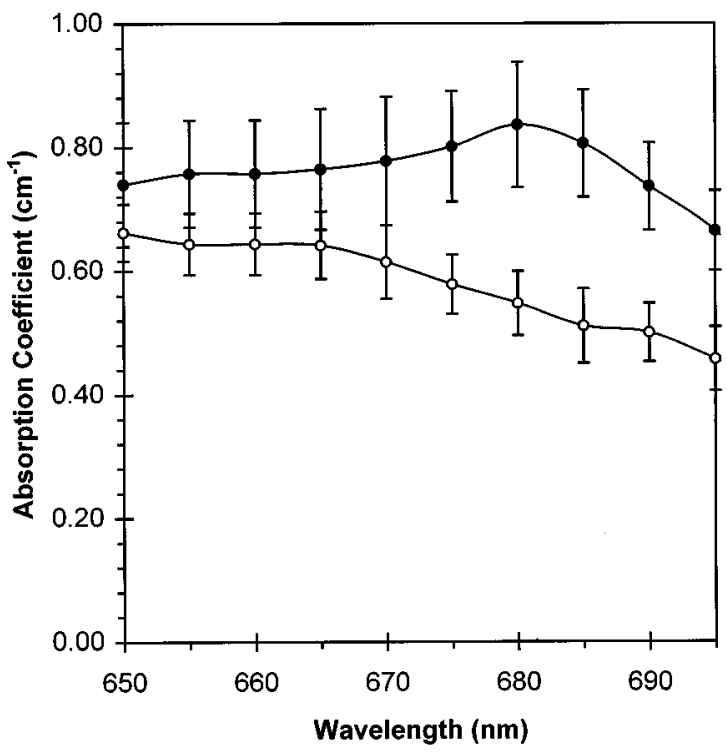

Fig. 1 Average absorption spectrum of the MS-2 fibrosarcoma acquired in vivo from mice before (open circles) and $1 \mathrm{~h}$ after (closed circles) the administration of $2.5 \mathrm{mg} / \mathrm{kg} \mathrm{b.w}$. of $\mathrm{AlPcS}_{2}$.

Three hours after the injection of $2.5 \mathrm{mg} / \mathrm{kg}$ b.w. of $\mathrm{AlPcS}_{2}$, no significant differences with respect to the data collected after $1 \mathrm{~h}$ of incubation are observed either in the absorption line shape or in the absolute values of the absorption coefficient (data not shown).

One hour after the injection of the higher drug dose $(5 \mathrm{mg} / \mathrm{kg}$ b.w.), again a very broad absorption peak is centered at $680 \mathrm{~nm}$, similar to that observed

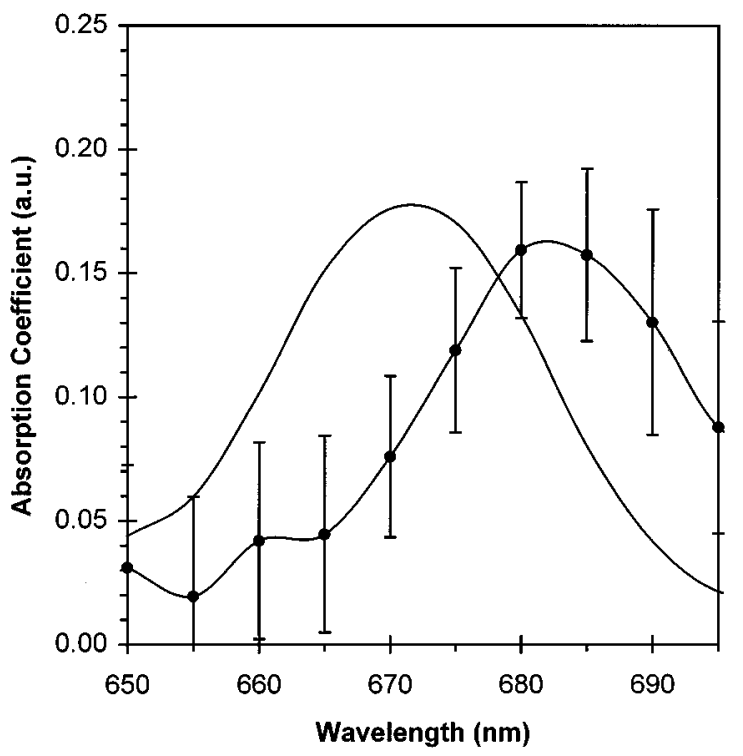

Fig. 2 Average absorption line shape of $A l P c S_{2}$ acquired in vivo $1 \mathrm{~h}$ after the administration of $2.5 \mathrm{mg} / \mathrm{kg} \mathrm{b.w}$. to mice bearing the MS-2 fibrosarcoma (circles) and absorption line shape of 2.5 $\mu \mathrm{g} / \mathrm{ml} \mathrm{AlPcS} 2$ in aqeous solution (solid line). 


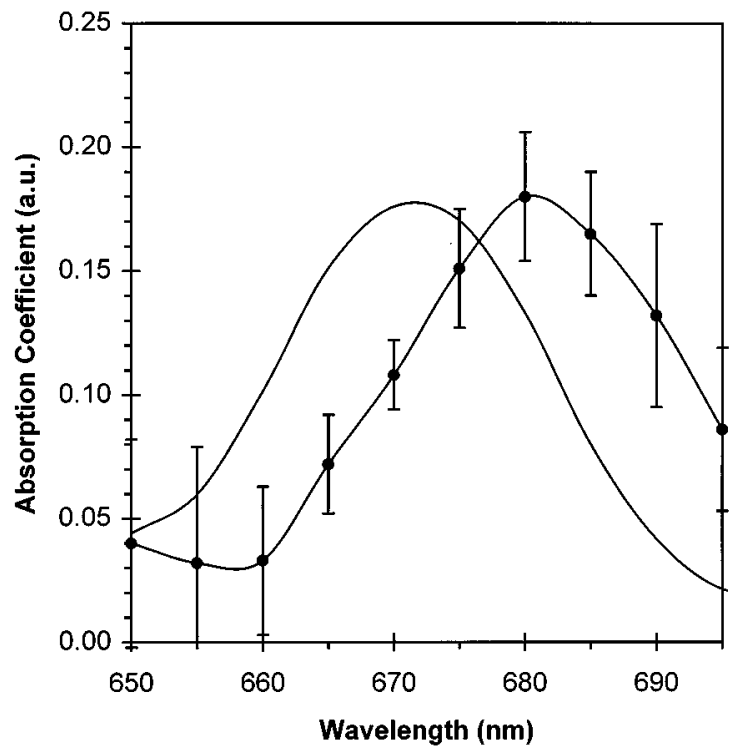

Fig. 3 Average absorption line shape of $\mathrm{AlPcS}_{2}$ acquired in vivo $1 \mathrm{~h}$ after the administration of $5 \mathrm{mg} / \mathrm{kg} \mathrm{b}$.w. to mice bearing the MS-2 fibrosarcoma (circles) and absorption line shape of 2.5 $\mu \mathrm{g} / \mathrm{ml} \mathrm{AlPcS}{ }_{2}$ in aqueous solution (solid line).

with the lower dose. After drug administration, the absorption coefficient exhibits an average increase of about $0.6 \mathrm{~cm}^{-1}$ at $680 \mathrm{~nm}$.

The absorption line shape of $5 \mathrm{mg} / \mathrm{kg} \mathrm{b.w}$. of $\mathrm{AlPcS}_{2}$, displayed in Figure 3, peaks at $680 \mathrm{~nm}$ and is not significantly different from the line shape measured after the injection of $2.5 \mathrm{mg} / \mathrm{kg}$ b.w.

\subsection{EX VIVO MEASUREMENTS}

For the ascites of mice injected with $\mathrm{AlPcS}_{2}$ and sacrificed $1 \mathrm{~h}$ later, the absorption spectrum is always centered between 682 and $684 \mathrm{~nm}$ and no line shape differences are observed independently of the drug dose up to $10 \mathrm{mg} / \mathrm{kg}$ b.w.

Very similar spectra are obtained also from the supernatant, again peaking at 682 to $684 \mathrm{~nm}$. Also, the values of the optical density due to the drug are comparable for the whole ascites and the supernatant. The main difference between the two types of samples is that in the spectra of the supernatant the noise level is lower, probably owing to the more limited turbidity. As a typical example, the spectrum of the supernatant measured after the administration of the highest dose $(10 \mathrm{mg} / \mathrm{kg} \mathrm{b.w.})$ is shown in Figure 4.

No reliable spectrum can be obtained from the isolated cells resuspended in saline. Only a very weak signal is measured. Owing to the noise, it is quite difficult to determine the exact position of the absorption maximum. However, it seems to be centered around $675 \mathrm{~nm}$ for any of the drug doses considered, from 1 to $10 \mathrm{mg} / \mathrm{kg}$ b.w. The spectrum collected from cells after the injection of the highest drug dose is displayed in Figure 5. Owing to the

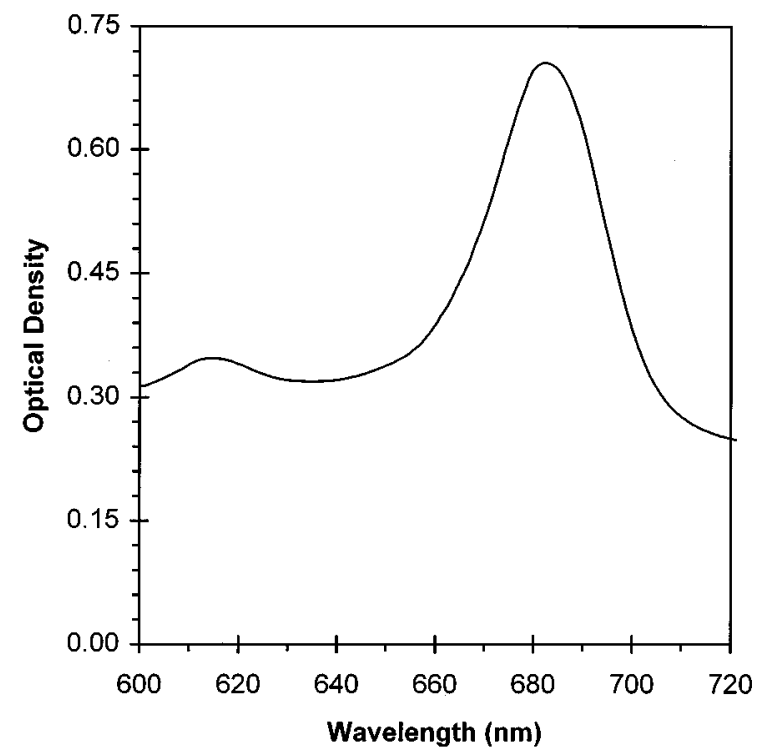

Fig. 4 Absorption spectrum of the supernatant measured ex vivo $1 \mathrm{~h}$ after the administration of $10 \mathrm{mg} / \mathrm{kg} \mathrm{b.w}$. AlPcS 2 to mice bearing the L1210 leukemia.

turbidity of the sample, a strong contribution to the detected signal comes from scattering. This was minimized by placing a suspension of untreated cells in the reference path of the spectrophotometer (see Sect. 2.4). However, the rapidly increasing signal present at short wavelengths in Figure 5 very likely originates from a residual fraction of scattered light, which could not be completely offset. If the cells or ascites of control animals is measured

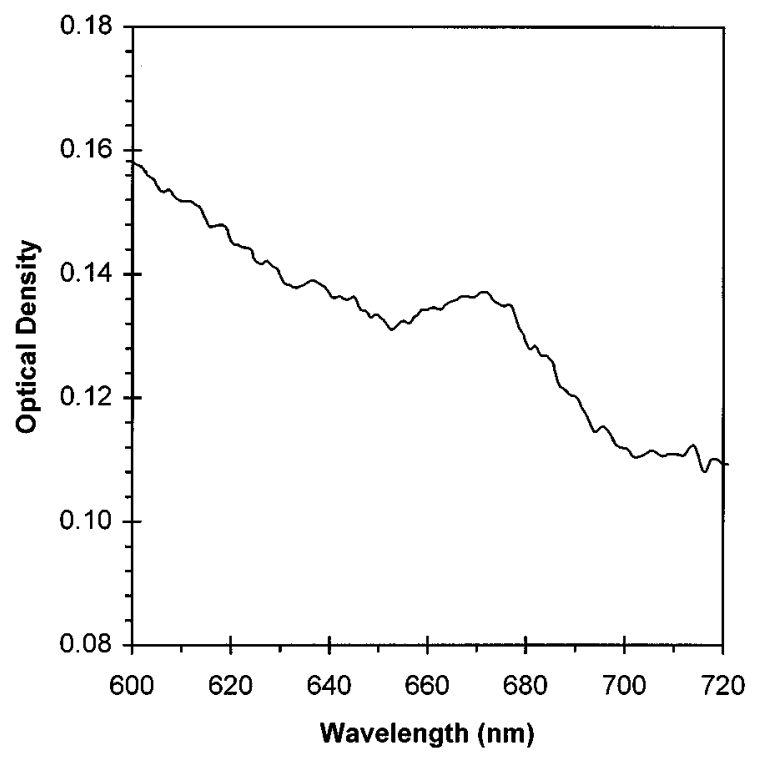

Fig. 5 Absorption spectrum of the cells measured ex vivo $1 \mathrm{~h}$ after the administration of $10 \mathrm{mg} / \mathrm{kg} \mathrm{b.w}$. AlPcS 2 to mice bearing the L1210 leukemia. 


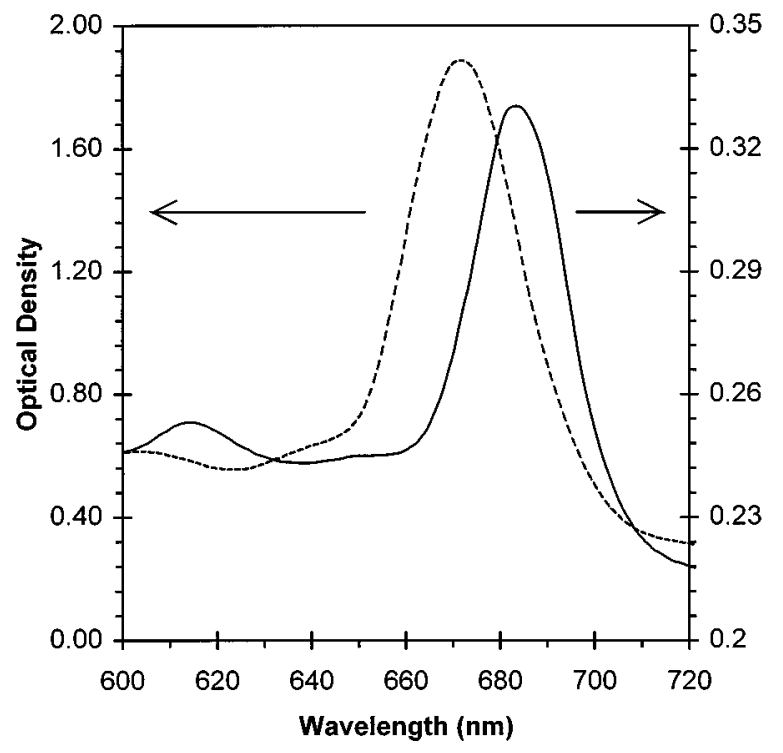

Fig. 6 Absorption spectrum of the supernatant after incubation ex vivo with $\mathrm{AlPcS}_{2}: 1 \mu \mathrm{g} / \mathrm{ml}$ (solid) and $10 \mu \mathrm{g} / \mathrm{ml}$ (dashed).

using saline as a reference, the same kind of rapidly decreasing spectrum, with no detectable peak, is obtained.

When the measurements are carried out after an incubation time of $3 \mathrm{~h}$, no meaningful differences in the results (both line shape and absorbance values) for the whole ascites, the supernatant, or the resuspended cells are observed with respect to the incubation time of $1 \mathrm{~h}$.

As shown in Table 1, when the supernatant of the untreated ascites is incubated ex vivo with $\mathrm{AlPcS}_{2}$, the absorption maximum shifts progressively toward the blue with increasing drug dose, from 683 to $684 \mathrm{~nm}$ at $0.25 \mu \mathrm{g} / \mathrm{ml}$ to $672 \mathrm{~nm}$ at $20 \mu \mathrm{g} / \mathrm{ml}$. Dependence on the phthalocyanine concentration is confirmed by Figure 6. Comparison of the two spectra in Figure 6 also reveals that, when the main absorption maximum is red shifted, the other minor peak as well is shifted from 605 to $615 \mathrm{~nm}$. As in the previous series of measurements, the whole ascites shows no significant differences in the spectral position of the absorption maximum compared with the supernatant incubated with the same drug dose.

Owing to the extreme weakness of the detected signal, it was not possible to measure a reliable absorption spectrum of cells incubated ex vivo with the two lower doses $(0.25$ and $0.5 \mu \mathrm{g} / \mathrm{ml})$. After incubation with 1 or $2.5 \mu \mathrm{g} / \mathrm{ml}$ of $\mathrm{AlPcS}_{2}$, the spectrum is centered between 670 and $675 \mathrm{~nm}$, as shown in Figure 7 for the latter concentration. A precise localization of the peak position is hampered by the significant noise level. At the highest doses (5, 10, and $20 \mu \mathrm{g} / \mathrm{ml}$ ), the absorption maximum is definitely centered around $672 \mathrm{~nm}$.

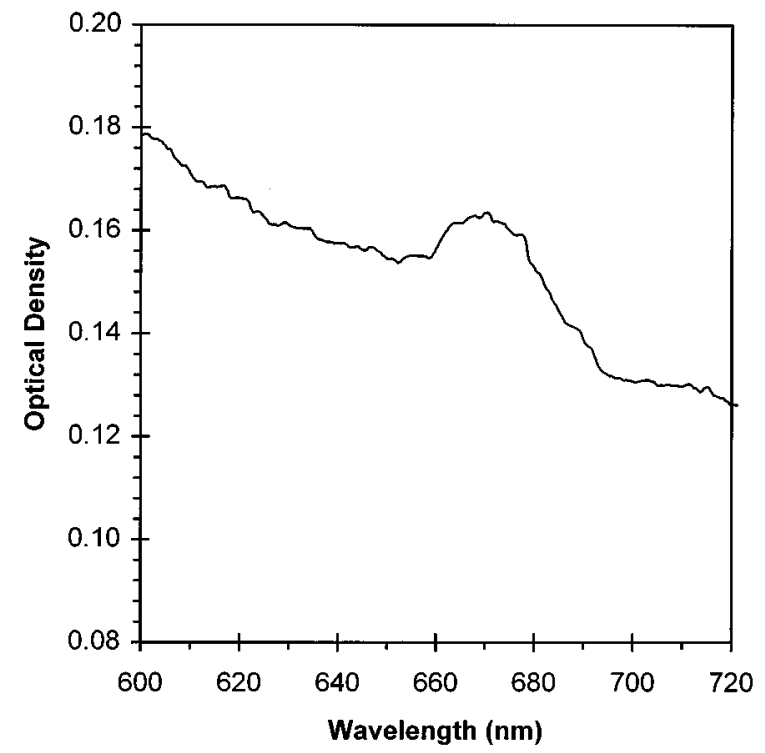

Fig. 7 Absorption spectrum of the cells after incubation ex vivo with $2.5 \mu \mathrm{g} / \mathrm{ml} \mathrm{AlPcS}$.

For the supernatant diluted 1:100 in saline before incubation, again a blue shift is observed with an increase in the drug dose, from 681 to $682 \mathrm{~nm}$ at the lowest dose considered $(0.25 \mu \mathrm{g} / \mathrm{ml})$ to $672 \mathrm{~nm}$ at $2.5 \mu \mathrm{g} / \mathrm{ml}$ (Table 2).

When the ascites is diluted after incubation with $20 \mu \mathrm{g} / \mathrm{ml}$, a progressive blue shift from 683 to 684 to 674 to $675 \mathrm{~nm}$ is caused by dilution. A similar blue shift is obtained for the supernatant, as shown in Table 3.

Finally, a blue-shifted absorption maximum is observed not only upon dilution, but also when the incubation of the supernatant itself is performed at very low concentrations with respect to the total volume (lower than a microgram per milliliter of total volume), as proved by the data reported in Table 4.

\section{DIsCUSSION}

The interfiber distance used in reflectance measurements is $0.8 \mathrm{~cm}$ and the optical properties of either treated or untreated tissue in the wavelength range considered are summarized by a transport scattering coefficient of about $10 \mathrm{~cm}^{-1}$ and an absorption coefficient $\mu_{\mathrm{a}} \approx 0.3$ to $1 \mathrm{~cm}^{-1}$. Under these experimental conditions, part of the diffusely reflected photons reaching the collection fiber have probably propagated not only in the tumor mass, having a diameter of about $1 \mathrm{~cm}$, but also in the surrounding tissue. In principle, the heterogeneity of the sampled volume does not satisfy the conditions for a correct application of diffusion theory to the interpretation of the reflectance data. However, in practice, the measured absorbance is an average value, the main contribution to which is expected to come from the neoplastic mass. 
For both the drug doses and the uptake times considered, the absorption line shape measured in vivo peaks in the range of 680 to $685 \mathrm{~nm}$ and is red shifted from 10 to $15 \mathrm{~nm}$ with respect to the spectrum in solution in various solvents. ${ }^{7}$ In a previous study, ${ }^{11}$ time-resolved reflectance was used to measure the absorption spectrum of $\mathrm{AlPcS}_{2}$ in vivo in the peritoneum of mice bearing an ascitic tumor (L1210 leukemia). The line shape obtained after the administration of $2.5 \mathrm{mg} / \mathrm{kg}$ b.w. was centered at 680 to $685 \mathrm{~nm}$ and was very similar to the one reported in the present work for the MS-2 fibrosarcoma. With a higher drug dose $(5 \mathrm{mg} / \mathrm{kg}$ b.w.), however, the spectral shape was found to depend on the single animal considered: it could be similar to the one obtained with the lower dose (peaking at 680 to $685 \mathrm{~nm}$ ), or significantly broader or even centered at 670 to $675 \mathrm{~nm}$. This trend toward the line shape typically observed in aqueous solution was attributed to weaker interactions between biological substrate and at least part of the sensitizer molecules, at high doses.

The results obtained with the two different tumor models after the administration of $5 \mathrm{mg} / \mathrm{kg} \mathrm{b.w}$. of $\mathrm{AlPcS}_{2}$ are only apparently contradictory. In fact for the ascitic tumor, the effective drug concentration in the peritoneum after intraperitoneal injection of the sensitizer is definitely higher than the concentration in a solid tumor after systemic administration of the same drug dose. This is confirmed by the analysis of the absorbance values. In fact after the injection of $2.5 \mathrm{mg} / \mathrm{kg} \mathrm{b.w.,} \mathrm{the} \mathrm{average} \mathrm{increase} \mathrm{of}$ the absorption coefficient $\mu_{\mathrm{a}}$ at 680 to $685 \mathrm{~nm}$ is about $0.3 \mathrm{~cm}^{-1}$ in the fibrosarcoma and higher than $1 \mathrm{~cm}^{-1}$ in the leukemia. Therefore, if a saturation phenomenon with $5 \mathrm{mg} / \mathrm{kg}$ b.w. is observed in the leukemia, similar effects are not expected in the fibrosarcoma. Moreover, in the fibrosarcoma, not only does the spectral shape show no remarkable changes going from 2.5 to $5 \mathrm{mg} / \mathrm{kg}$ b.w., but also the increase of the absorption coefficient doubles with the drug dose, suggesting again that the interactions with the environment are similar at the two doses considered.

Concerning the spread of measured values, as shown by the comparison of Figures 2 and 3, the standard deviations are rather lower for 5 than for $2.5 \mathrm{mg} / \mathrm{kg} \mathrm{b.w}$. Since the absorption line shape of the drug in vivo is obtained by subtracting the spectra of untreated animals from those of treated animals, this is possibly due to the higher increase in absorbance after the injection of the higher dose, which makes the subtraction less sensitive to the spreading of measured values for treated and untreated animals.

The results obtained in this study for the fibrosarcoma and previously for the leukemia ${ }^{11}$ indicate that the red shift of the absorption spectrum in vivo depends neither on the particular nature of the tumor model under study, nor on the type of tissue involved. In fact, it is observed in both solid and ascitic tumors with different locations. At the same time, a similar spectral change could not be induced in solution in different solvents nor in the presence of detergent micelles, ${ }^{7}$ suggesting a basic involvement of the biological substrate.

The red shift observed in the absorption spectrum in vivo explains also the similar behavior of the action spectrum of $\mathrm{AlPcS}_{2}$ for the photodynamic therapy (PDT) of tumors in mice. ${ }^{6,11}$ Moreover, it is probably common to other phthalocyanines. In this regard, it should be considered that the action spectrum of tetrasulfonated zinc phthalocyanine for PDT in rats proved to be red shifted with respect to the absorption spectrum of the drug in solution, ${ }^{15}$ suggesting a red shift of its absorption spectrum in vivo as well.

To better investigate the causes of the spectral shift, experiments were performed by measuring the absorption spectrum under experimental conditions that moved progressively away from the situation in vivo. The spectral line shape was evaluated ex vivo for $\mathrm{AlPcS}_{2}$ incubated either in vivo or ex vivo. In both cases, different drug-to-supernatant (or drug-to-ascites) concentration ratios were considered. Moreover, for the incubation ex vivo, the drug dose was varied not only with respect to the supernatant (or ascites) volume, but also with respect to the total solution volume, while keeping the drugto-supernatant (or ascites) ratio constant.

When the incubation is performed in vivo and the measurement ex vivo, up to doses of $10 \mathrm{mg} / \mathrm{kg}$ b.w. the line shape is always red shifted. If the absorbance on the peak is considered, it is found that similar values are obtained with the injection of 10 $\mathrm{mg} / \mathrm{kg}$ b.w. and after incubation ex vivo with 10 to $20 \mu \mathrm{g}$ of $\mathrm{AlPcS}_{2}$ per milliliter of supernatant when the supernatant is diluted 1:10 in saline. This seems to indicate that the concentration is similar in the two situations, and in both cases the line shape is red shifted (see Table 1), suggesting an agreement between results of the experiments carried out with incubation in vivo and ex vivo.

As described above, if a dose of $5 \mathrm{mg} / \mathrm{kg}$ b.w. is administered in vivo, but the ascites is measured ex vivo, the spectrum is red shifted. In contrast, as mentioned previously, the absorption line shape measured in vivo after the injection of the same drug dose to mice bearing the L1210 leukemia depends on the single animal considered. Actually, it can be centered around 670 to $675 \mathrm{~nm}$ or 680 to 685 $\mathrm{nm}$ or even show both peaks. ${ }^{11}$ This different behavior supports the hypothesis of an uneven distribution of the drug in the peritoneum, with areas where high concentrations can be reached, while the situation ex vivo is obviously homogeneous. 
This would explain both the variability of the line shape and the observation of short-wavelength absorption in some animal when measurements are performed in vivo.

The data reported in Tables 1 and 2 indicate that the red shift of the absorption spectrum can be observed also after incubation of the ascites ex vivo, but, similarly to what is found in vivo, only low drug doses seem to elicit such a spectral change. As shown in Tables 1 and 2, analogous results are obtained when the drug-to-supernatant ratio is kept constant, even if this corresponds to different values of the ratio between drug amount and total volume of the aqueous solution. This trend again seems to strengthen the hypothesis, previously made, ${ }^{11}$ that at high drug doses a saturation effect is present and some of the sensitizer molecules are not strictly bound to the substrate. Hence they experience an environment similar to the aqueous one and their absorption maximum peaks around 670 to $675 \mathrm{~nm}$.

However, the outcomes of the last two series of measurements, reported in Tables 3 and 4, suggest that the interactions between drug and substrate, which lead to the bathochromic shift, can be altered by modifying the ratio between substrate and water molecules. In fact, by diluting the ascites (or the supernatant) after incubation or adding the same amount of drug and supernatant to increasing volumes of water, a progressive shift to shorter wavelengths is observed.

When reliably measured, the spectrum of L1210 cells incubated either in vivo or ex vivo is always centered between 670 and $675 \mathrm{~nm}$. This could be an indication that the red shift is not due to binding at intracellular sites. However, as a consequence of resuspension of isolated cells in saline, part of the drug molecules might be released from cells, reaching the aqueous medium. In this case, the interactions with water might well be responsible for the observed short-wavelength absorption. Moreover, it should be taken into account that, after centrifugation, cells were only isolated and resuspended. They were not washed. Therefore the weak binding of $\mathrm{AlPcS}_{2}$ molecules at outer cellular sites might break upon resuspension, releasing the drug in an aqueous environment. Cells were not washed since washing led to an unmeasurable absorption spectrum for the sensitizer. This seems to be a clear indication of drug release and to confirm that release, at least partially, may happen even upon resuspension without washing.

As a consequence of these observations, no definite conclusion can be drawn about the eventual effect of intracellular binding on the absorption properties of $\mathrm{AlPcS}_{2}$ in vivo. Concerning cells, it should be noted that, even though the action spectrum of chloroaluminum phthalocyanine in Chinese hamster cells is centered around $680 \mathrm{~nm},{ }^{16}$ the action spectrum of $\mathrm{AlPcS}_{2}$, incorporated in cells of two different lines does not show any significant shift, ${ }^{17}$ which is in agreement with the results of the present study. On the other hand, the extracellular biological substrate clearly proved to contribute to, if not to be solely responsible for, the spectral shift observed in the absorption spectrum of $\mathrm{AlPcS}_{2}$, which is in accord with the dominant role of the extracellular matrix observed in vascular PDT with chloroaluminum phthalocyanine. ${ }^{18}$

As a more general conclusion, when distinct kinds of environments are present, the interactions and consequently the absorption properties of $\mathrm{AlPcS}_{2}$ seem to be the result of a dynamic equilibrium dependent not only on the amount of drug, but also on the relative abundance of the different accessible substrates and solvents.

\section{Acknowledgments}

This work was partially supported by the National Council for Research (Italy), under the Special Project "Applicazioni Cliniche della Ricerca Oncologica."

\section{REFERENCES}

1. I. Rosenthal, "Phthalocyanines as photodynamic sensitizers," Photochem. Photobiol. 53, 859-870 (1991).

2. H. L. L. M. van Leengoed, N. van der Veen, A. A. C. Versteeg, R. Ouellet, J. E. van Lier, and W. M. Star, "In vivo photodynamic effects of phthalocyanines in a skin-fold observation chamber model: role of central metal ion and degree of sulfonation," Photochem. Photobiol. 58, 575-580 (1993).

3. C. J. Tralau, A. R. Young, N. P. J. Walker, D. I. Vernon, A. J. MacRobert, S. B. Brown, and S. G. Bown, "Mouse skin photosensitivity with dihaematoporphyrin ether (DHE) and aluminium sulphonated phthalocyanine (AlSPc): a comparative study," Photochem. Photobiol. 49, 305-312 (1989).

4. K. Berg, J. C. Bommer, and J. Moan, "Evaluation of sulfonated Aluminum phthalocyanines for use in photochemotherapy. A study on the relative efficiencies of photoinactivation," Photochem. Photobiol. 49, 587-594 (1989).

5. G. Canti, P. Franco, O. Marelli, R. Cubeddu, P. Taroni, and R. Ramponi, "Comparative study of the therapeutic effect of photoactivated hematoporphyrin derivative and aluminum disulfonated phthalocyanines on tumor bearing mice," Cancer Lett. 53, 123-127 (1990).

6. G. Canti, D. Lattuada, E. Leroy, R. Cubeddu, P. Taroni, and G. Valentini, "Action spectrum of photoactivated phthalocyanine $\mathrm{AlS}_{2} \mathrm{Pc}$ in tumor bearing mice," Anti-Cancer Drugs 3, 139-142 (1992).

7. M. Ambroz, A. J. MacRobert, J. Morgan, G. Rumbles, M. S. C. Foley, and D. Phillips, "Time-resolved spectroscopy and intracellular imaging of disulphonated aluminium phthalocyanine," J. Photochem. Photobiol. B 22, 105-117 (1993).

8. B. C. Wilson and S. L. Jacques, "Optical reflectance and transmittance of tissues: principles and applications," IEEE J. Quantum Electron. 26, 2186-2199 (1990).

9. T. J. Farrell, M. S. Patterson, and B. Wilson, "A diffusion theory model of spatially resolved, steady-state diffuse reflectance for the noninvasive determination of tissue optical properties in vivo," Med. Phys. 19, 879-888 (1992).

10. B. Wilson, E. M. Sevick, M. S. Patterson, and B. Chance, "Time-dependent optical spectroscopy and imaging for biomedical applications," Proc. IEEE 80, 918-930 (1992).

11. R. Cubeddu, G. Canti, M. Musolino, A. Pifferi, P. Taroni, and G. Valentini, "In vivo absorption spectrum of disulphonated Aluminium phthalocyanine in a murine tumour model," J. Photochem. Photobiol. B 34, 183-189 (1996).

12. R. Cubeddu, M. Musolino, A. Pifferi, P. Taroni, and G. Valentini, "Time-resolved reflectance: a systematic study for the application to the optical characterization of tissues," IEEE J. Quantum Electron. 30, 2421-2430 (1994). 
13. M. S. Patterson, B. Chance, and B. C. Wilson, "Timeresolved reflectance and transmittance for the noninvasive measurement of tissue optical properties," Appl. Opt. 28, 2331-1336 (1989).

14. L. S. Lasdon, A. D. Waren, A. Jain, and M. Ratner, “Design and testing of a generalized reduced gradient code for nonlinear programming," ACM Trans. Math. Software 4, 34-50 (1978).

15. J. Griffiths, J. Cruse-Sawyer, S. R. Wood, J. Schonfield, S. B. Brown, and B. Dixon, "On the photodynamic therapy action spectrum of zinc phthalocyanine tetrasulphonic acid in vivo," J. Photochem. Photobiol. B 24, 195-199 (1994).

16. E. Ben-Hur and I. Rosenthal, "Action spectrum (600-700 nm) for chloroaluminum phthalocyanine-induced phototoxicity in Chinese hamster cells," Lasers Life Sci. 1, 79-86 (1986).

17. J. Moan, K. Berg, J. C. Bommer, and A. Western, "Action spectra of phthalocyanines with respect to photosensitization of cells," Photochem. Photobiol. 56, 171-175 (1992).

18. F. Adili, R. G. S. van Eps, S. J. Karp, M. T. Watkins, and G. M. LaMuraglia, "Differential modulation of vascular endothelial and smooth muscle cell function by photodynamic therapy of extracellular matrix: novel insights into radicalmediated prevention of intimal hyperplasia," J. Vasc. Surg. 23, 698-705 (1996). 